In Paul Lodge and Tom Stoneham, eds., Locke and Leibniz on Substance (Oxford:

Routledge, 2015). Penultimate version.

Donald L. M. Baxter

University of Connecticut

January 6, 2014

\title{
Hume on Substance: A Critique of Locke
}

The ancient theory of substance and accident is supposed to make sense of complex unities in a way that respects both their unity and their complexity. On Hume's view such complex unities are only fictitiously unities. This result follows from his thoroughgoing critique of the theory of substance.

I will characterize the theory Hume is critiquing as it is presented in Locke. My reading of Locke will follow Jonathan Bennett in presupposing what he calls the "Leibnizian interpretation" of the relevant texts. ${ }^{1}$ Locke uses the word 'substance' in two senses. In one sense, an individual or mass such as "a Man, Horse, Gold, Water, etc." is a substance. In another sense a substance is the principle of unity and identity for an individual in which its accidents such as "Colour or Weight" inhere. It is a "Substratum, " a "pure Substance in general" (ECHU 2.23.1-4). Call substance in the first sense "individual substance" and in the second sense "pure substance." In the New Essays Leibniz locates both senses in Locke. ${ }^{3}$

${ }^{1}$ Bennett 1987: 197. Ayers' alternative interpretation is motivated by his assumption that the Leibnizian interpretation takes Lockean substratum to be like prime matter. I find this a problematic assumption. Substratum is meant to be a principle of unity; something divisible like prime matter would need a principle of unity. Ayers 1977: 78.

${ }^{2}$ Locke tends rather to use "Substance in general" and "particular sorts of Substances" for the two senses, but I find his terminology less clear and more cumbersome.

${ }^{3} \mathrm{NE}$ 145-6, 218. 
Hume's view in the Treatise is that pure substance is a fiction, as is complex individual substance. Only simple individual substances are real. Surprisingly, however, they turn out to be the so-called accidents that were supposed to inhere in a pure substance, namely qualities and perceptions.

I will discuss the seven main parts of Hume's view: (I) that we have no idea of pure substance, (II) that there is no complex individual substance, except in a loose sense, (III) that the fiction of complex individual substance arises in a way parallel to that of the fiction of identity through time, and (IV) results in the fiction of pure substance, (V) that simple qualities and perceptions satisfy the definition of individual substance, (VI) that there is no such thing as inherence, and (VII) that there is no such thing as pure substance.

Hume's views on substance are often mentioned without being discussed in detail. Kemp Smith, Stroud, and Garrett, for example, mostly summarize various claims of Hume in the course of expounding on his theory of the idea of personal identity. ${ }^{4}$ In contrast, I will attempt to present a systematic treatment of Hume on substance.

\section{No idea of pure substance}

Locke holds that an individual substance consists of a pure substance plus the accidents that inhere in the pure substance. Thus the idea of an individual substance is a complex idea consisting of an idea of a pure substance plus ideas of its accidents. "The Ideas of Substances are such combinations of simple Ideas, as are taken to represent distinct particular things subsisting by themselves; in which the

\footnotetext{
${ }^{4}$ Kemp Smith 1941: Ch. 23, Stroud 1977: Ch. 6, Garrett 1997: Ch. 8.
} 
supposed, or confused Idea of [pure] Substance, such as it is, is always the first and chief" (ECHU, 2.12.6). Hume, following Locke, takes the accidents of an individual substance to be its qualities. When Hume denies that we have an idea of substance, he is not denying that we have an idea of a collection of qualities (THN 1.4.3.5). Thus it must be the idea of pure substance that he is questioning. He finds that we can have no impression from which such an idea could be copied. His objection echoes Berkeley's: ${ }^{5}$

1. All we have impressions of are at root either sensory qualities or passions.

2. Qualities and passions are accidents, on the substance/accident theory.

3. Therefore, we cannot have an impression of pure substance.

4. Therefore, by the Copy Principle, we have no idea of pure substance.

Hume later renews this objection, making clear the Berkeleyan presupposition that ideas represent by resembling. Since an impression is nothing like a pure substance, it cannot represent a pure substance. Therefore, there is no impression of a pure substance, and so no idea of one. ${ }^{6}$ With this claim Locke would agree: "So that of [pure] Substance, we have no Idea of what it is, but only a confused obscure one of what it does" (ECHU, 2.13.19).

\section{No complex individual substance}

As for individual substance, the definition that Hume uses is "something which may exist by itself' (THN 1.4.5.5). This accords with Locke's assumption that the pure substance is for the accidents the "Cause of their Union, as makes the whole subsist

\footnotetext{
5 THN 1.1.6.1. PHK I.8.

6 THN 1.4.5.3.
} 
of itself," whereas the accidents cannot "subsist by themselves" (ECHU, 2.23.6, 2.23.1).

When appealing to an argument by Malezieu during his discussion of infinite divisibility, Hume concludes, "But the unity, which can exist alone, and whose existence is necessary to that of all number, is of another kind, and must be perfectly indivisible, and incapable of being resolv'd into any lesser unity" (THN 1.2.2.3, my emphasis). So something that can exist by itself is perfectly indivisible. So there are no complex individual substances, only simple ones. I will explain this argument. Radical as the conclusion is, it is not quite as radical as it sounds. There will be a loose sense in which complex individual substances exist.

When arguing that some parts of space are simple Hume adds "another argument propos'd by a noted author, which seems to me very strong and beautiful" (THN 1.2.2.3). It is based on the following passage in Malezieu:

[9] Moreover, when I carefully consider the existence of things, I very clearly understand that existence pertains to units and not to numbers. I shall explain my meaning.

[10] Twenty men exist only because each man exists; number is only an extrinsic denomination, or better, a repetition of units to which alone existence pertains. ${ }^{7}$ (my emphasis)

\footnotetext{
${ }^{7}$ Malezieu (1705), in a section of Book 9 entitled "Réflexions sur les incommensurables." The translation is from Ryan 2012: 110.
} 
Only units exist. A number of things is not a unit, but rather is many repeated units. Consequently a number of things does not strictly speaking exist, except insofar as the repeated units each exist. Hume puts it this way:

'Tis evident, that existence in itself belongs only to unity, and is never applicable to number, but on account of the unites [units], of which the number is compos'd. Twenty men may be said to exist; but 'tis only because one, two, three, four, \&c. are existent; and if you deny the existence of the latter, that of the former falls of course. (THN 1.2.2.3)

From this insight, a Humean argument can be constructed.

(1) To be complex is to have numerically distinct parts.

(2) Anything with numerically distinct parts is many things, not a single thing.

(3) Only single things really exist.

(4) So nothing complex really exists.

Hume takes premise (1) to be true by definition. Premises (2) and (3) are part of the Malezieu view that Hume endorses.

One might try to resist (1) by appealing to Armstrong's claim that there can be complexes that lack parts but have constituents--the key difference being that no two complexes can have all the same parts, whereas two distinct complexes can have all the same constituents. ${ }^{8}$ However, Hume's argument uses 'parts' in the most general sense, so the argument would be the same even if "parts or constituents" were substituted for "parts" in (1) and (2). The key is the numerical distinctness of

${ }^{8}$ Armstrong 1991: 189-90. 
the composing things, not whether composition is extensional. In any event, Locke could not agree that a complex substance has only constituents in Armstrong's sense, since one of the constituents would be the pure substance, i.e., the principle of unity and identity. If two complexes had all the same constituents including the same pure substance, then they would be identical and not two.

Understanding the full generality of (2) requires looking at the examples that Hume gives: (i) "any determinate quantity of extension," (ii) "twenty men," (iii) "the whole globe of the earth," (iv) "the whole universe." We may be tempted to think that (ii) and perhaps (iv) are pluralities as opposed to (i) and (iii) which are wholes with parts. Locke would seem to be thinking this way when he distinguishes single substances from collective substances (ECHU, 2.12.6). However, Hume discusses all of these as examples of things whose unity is "merely a fictitious denomination," and makes no distinction between them. They are all cases of "number" composed of "unites" (THN 1.2.2.3). Some confirmation is provided in the Dialogues where Cleanthes says "the uniting of these parts into a whole, like the uniting of several distinct countries into one kingdom, or several distinct members into one body, is performed merely by an arbitrary act of the mind, and has no influence on the nature of things"(DNR 9). Hume assimilates wholes to mere pluralities.

Note that by 'plurality' I mean several things collectively, not some single thing that is somehow made up of them. A way to understand Hume's assimilation is to try to see the strangeness of the contemporary view that the whole is a single thing in addition to its parts. On that view to hold a six-pack of beer is automatically to hold seven items--the six cans plus the six-pack--even neglecting the plastic 
yoke. ${ }^{9}$ But it would seem that the six-pack just is the six cans and nothing in addition. If so, then the six-pack is really a plurality, and not a single thing at all. ${ }^{10}$

An obstacle to understanding Hume's view is our penchant for confusing united with unitary. United things are many things in some relation. A unitary thing is a single thing. ${ }^{11}$ When Hume talks of unity or being one, he is talking of unitariness or being unitary.

Premise (3) is a version of the ancient tenet that being and unity are convertible. ${ }^{12}$ Leibniz thought it could be seen to be true just by paying attention to a shift in emphasis: "That what is not truly one entity is not truly one entity either."13 Note that the use of a grammatically singular expression to refer to many things collectively (e.g. 'plurality', 'multitude', 'aggregate'), does not entail that a plurality, say, really exists. However referred to, they are many things, strictly speaking.

One might think that in his version of the Malezieu argument, Hume meant only that wholes depend on each and all their parts, not that wholes are their parts collectively. ${ }^{14}$ However such a dependence between distinct things, a whole and a part, contravenes Hume's central principle that there are no necessary connections

\footnotetext{
${ }^{9}$ Even David Lewis, who argues that mereological composition is analogous to numerical identity, still takes a mereological sum to be something in addition to its parts, numerically distinct from each (1991: 81-87).

${ }^{10}$ I argue that to have the six-pack be genuinely a single thing as well, would require that existence as a single thing be relativized to what I call "counts." See Baxter 1988.

11 Cf. Hume's observation that we tend to confuse an identical object with a succession of related objects, even though "this to an accurate view affords as perfect a notion of diversity, as if there was no manner of relation among the objects" (THN 1.4.6.6).

12 Aristotle 1941: Metaphysics, XI.3, 1061a16.

13 LA 121. See also NE 146 and Baxter 1995.

14 Garrett 2009: 437.
} 
between distinct things; distinct things are separable. ${ }^{15}$ I will return to this point in section VI.

Interpreting Hume as denying the existence of complex individuals is not quite as radical as it sounds. It is certainly not an interpretation to be refuted by appealing to Hume's references to complex individuals. For instance, Hume says, "For as the compound idea of extension, which is real, is compos'd of such ideas [i.e. simple ones]; were these so many non-entities, there wou'd be a real existence compos'd of non-entities; which is absurd" (THN 1.2.3.14). Here the complex individual in question is an idea--the compound idea of extension. Here Hume says that this idea is real. So, the objection goes, he thinks at least one complex individual is real. So it exists, contra my interpretation. ${ }^{16}$

However, Hume has already explained in the Malezieu passage what to make of references to complex individuals. Twenty men "may be said to exist" if each of the twenty exists. Though saying that a plurality exists is strictly false, saying it can be appropriate if this member of the plurality exists and that one exists and that one exists, etc. and if, perhaps, these many are related in some salient way. The same goes for any purportedly complex individual. In taking it to exist, the several individuals composing it "may be consider'd as an unite." But Hume is clear that the unity is fictitious. "That term of unity is merely a fictitious denomination, which the mind may apply to any quantity of objects it collects together; nor can such an unity any more exist alone than number can, as being in reality a true number" (THN

15 THN 1.1.7.3, 1.4.5.5.

16 I'm grateful to Jani Hakkarainen for this objection. 
1.2.2.3). Its unity is fictitious, but given the fiction we may appropriately say of the complex individual that it exists.

Take, for example, Hume's query,

On the contrary, does he not evidently perceive, that from the union of these points there results an object, which is compounded and divisible, and may be distinguish'd into two parts, of which each preserves its existence distinct and separate, notwithstanding its contiguity to the other? (THN 1.2.4.6)

An object "may be said to exist" if what are regarded as its parts are contiguous.

In the same way, even a complex substance "may be said to exist" as in the following passage:

I have already prov'd, that we have no perfect idea of substance; but that taking it for something, that can exist by itself, 'tis evident every perception is a substance and every distinct part of a perception a distinct substance. (THN 1.4.5.24)

On the assumption that a substance is unitary, this passage appears to commit Hume to unitary perceptions having unitary perceptions as parts. However, Hume is explicitly rejecting that assumption in this passage. His talk of proving "that we have no perfect idea of substance" refers back to "Of the antient philosophy" where he argues that in our idea of a substance we only feign its unity. ${ }^{17}$ Nonetheless a complex substance, such as a complex perception, "may be said to exist." Having done that, the complex perception meets the criterion of a substance: ability to exist

17 THN 1.4.3.5. See my section III. 
by itself. That is, the many perceptions taken collectively that are "it" can exist without any other thing. And, of course, so can each of the many perceptions taken individually.

All Hume's references to complex individuals are thus consistent with his Malezieunian conclusion that nothing complex really exists, strictly speaking. It follows that a Lockean individual substance which is a complex of pure substance plus accidents does not exist, strictly speaking.

\section{The fiction of complex individual substance}

For Hume the idea of a purported individual substance is really just a collection of ideas of various qualities. For instance the idea of a peach is just the ideas of its color, taste, figure, solidity, etc. ${ }^{18}$ And for Hume there is no real unity or existence to such collections other than the individual existences of their members. How does the fiction arise that such collections of qualities are unitary individuals?

The question would seem to apply as well to Locke's view. He speaks of the several ideas of accidents used collectively to think of an individual substance, "which by inadvertency we are apt afterward to talk of and consider as one simple Idea, which is indeed a complication of many Ideas together" (ECHU, 2.23.1). Given that Locke often uses 'idea' to refer to qualities qua objects of thought, there is the same problem of what makes us take many qualities to instead be a unitary individual.

Even though a whole is just a plurality that does not strictly speaking exist, the many individuals can be considered as a unit and so the purported whole can

18 THN 1.4.3.5. 
appropriately be said to exist. Presumably the degree to which they are related is reflected in the degree to which the mind tends to consider them a unity. ${ }^{19}$ Hume explores these degrees in his discussion of the idea of personal identity, moving from a mass of matter, to an assemblage for some purpose, to an organic unity. ${ }^{20} \mathrm{In}$ "Of the antient philosophy" he explains how the relations between several qualities may be so strong that the mind is first moved to attribute simplicity to the qualities taken collectively, and then is moved to feign a pure substance to justify this attribution. He compares this tendency to our tendency to attribute identity to a succession of related objects. ${ }^{21}$

There is some temptation to think that sometimes by 'simplicity' Hume just means identity at a time. However, as we shall see, it is what we might call simplicity-in-complexity that parallels Hume's account of identity through time, not just simplicity itself. Simplicity is just unitariness, not a medium betwixt unity and number as identity must be. ${ }^{22}$

Let me first summarize Hume's account of the idea of identity through time, then describe its application to a succession of related objects. Then I can bring out the parallels in his account of attributing simplicity to a plurality.

\footnotetext{
19 Cf. LA 121.

20 THN 1.4.6.8-12.

21 THN 1.4.3.5 and its summary at THN 1.4.6.22.

22 Only non-complex things are unitary (THN 1.2.2.3). To suppose something to be simple is to suppose it to be "ONE thing" (1.4.3.2). A couple of places where simplicity is unitariness, though only in some respect, is THN 1.1.7.18, where Hume talks of the simplicity of figure and body figured (even though the body itself is complex) and THN 1.4.5.14 where Hume says impressions of touch are simple (except when considered with regard to their extension). I'm grateful to Jani Hakkarainen for discussion.
} 
For Hume, the idea of identity is the idea of "the invariableness and uninterruptedness of any object thro' a suppos'd variation of time" (THN 1.4.2.30). To be invariable and uninterrupted is to be steadfast, where something steadfast is not a succession of things. To have duration in time is to be a succession. ${ }^{23}$ So the idea of identity is the fiction of being somehow both a succession and not a succession. Hume brings in successiveness and steadfastness as surrogates for being many distinct things and being one single thing. Identity, for Hume, is essentially a combination of being one thing and being many things. It is essentially identity-indifference, as the British Idealists put it. ${ }^{24}$ We heirs of Frege are dismissive of this notion, but we shouldn't be. Hume's account of identity is meant to respond to a fundamental problem with identity that Fregeans overlook--a problem I've termed "Hume's Difficulty." 25 The problem is how we can represent there as being something that is perhaps one thing and perhaps many distinct things. The problem is raised by the fact that we can be unsure of an identity. We can meet someone and later meet someone and be unsure whether or not they are identical. Furthermore we can imagine them either way. This ability to alternate between thinking of them as one person and thinking of them as two distinct persons is what Hume is trying to capture in his idea of identity. He calls it an idea of a "medium betwixt unity and

\footnotetext{
${ }^{23}$ Thus for Hume there are two ways to take up time: being a steadfast object and being a succession with duration. See Baxter 2008: 30-31.

${ }^{24}$ See Bradley 1897: Chs. 2 and 3, Appendix Note C; Bradley 1928: Bk. 1, Ch. 5, Secs. 1-9.

${ }^{25}$ Baxter 2008: 54, 83.
} 
number." More accurately it is an idea that alternates between being a thought of something as one single thing and as many distinct things. ${ }^{26}$

Once one has the idea of identity, it is often applied to distinct but closely related objects in succession. Perhaps they resemble or are causally connected. One's successive ideas of them are thus connected by the principles of association of ideas. As a result, thinking of the succession gives the same feeling to the mind as it has when contemplating a steadfast object. The easy transition of the mind between one idea and the next feels just about the same as the feeling of repose when the mind continues the same idea, as it does when continuing to think of a steadfast object. ${ }^{27}$ In such a case the idea of identity is substituted and so the succession in question is alternately viewed with an accurate idea of it as many distinct things and with a fictitious idea of it as one single thing. ${ }^{28}$

Hume goes on to give a parallel account of the attribution of simplicity to a bundle of qualities. The relation between them is the one Locke noted: constantly occurring together, which for Hume is a combination of contiguity and causation. ${ }^{29}$ Hume says that the action of the mind in considering a simple object feels very similar to that of contemplating many strongly related objects.

\footnotetext{
26 THN 1.4.2.29.

27 THN 1.4.2.33, 1.4.3.3, 1.4.6.16.

28 I note that it is hard to reconcile Hume's characterization of numerical identity as a medium betwixt unity and number with his contention that numerical identity is the opposite of difference in number (THN 1.1.5.10). I'm grateful to Annemarie Butler for pointing out the import of this passage.

${ }^{29}$ ECHU, 2.23.1. THN 1.1.6.2, 1.4.5.12. At THN 1.4.5.12 Hume uses 'inseparability' to refer to the relation of cause and effect, but he does not mean inseparability in the metaphysical sense that by his Real Separability Principle is equivalent to numerical identity. He has already made clear that cause and effect are not inseparable in this sense (THN 1.3.3.3).
} 
We entertain a like notion with regard to the simplicity of substances, and from like causes. Suppose an object perfectly simple and indivisible to be presented, along with another object, whose coexistent parts are connected together by a strong relation, 'tis evident the actions of the mind, in considering these two objects, are not very different. (THN 1.4.3.5)

For Hume the idea of simplicity does not have the complexity of the idea of identity. A simple thing is just one single thing, and regarding it as simple is to regard it as a single thing. There is no alternation between incompatible ideas in the idea of simplicity. However, in the case at hand, Hume cannot mean that the idea of simplicity is simply substituted for the idea of complexity when contemplating the many strongly related things. For he says, "But the mind rests not here." The mind goes on to be struck by the multiplicity of the objects it is trying to regard as one simple thing. "Whenever it views the object in another light, it finds that all these qualities are different, and distinguishable, and separable from each other." So it feigns an unknown something to justify the idea of the bundle's unity-something that "may give the compound object a title to be call'd one thing, notwithstanding its diversity and composition" (THN 1.4.3.5). This feigned, unknown something is pure substance.

If this account is meant to be parallel to the account of substituting the idea of identity for the idea of many things in succession, then Hume must mean that, rather than simply substituting the idea of simplicity, we alternate between the idea of simplicity and the idea of complexity. He could not mean anything else. Several 
coexistent things are too obviously different from something simple. Take a peach or a melon and contrast it with a spatially minimal point. The latter is simple. The former obviously is not, and it would be difficult blithely to let an idea representing the peach as simple to be all there is to it. The causes of substituting the idea of simplicity are not strong enough, apparently, to just give up on the evident complexity. The only recourse is to alternate between the idea of simplicity and the idea of complexity just as happens in the idea of identity through time. In the present case this would also be an alternation between a simple idea representing the peach as one single thing and a collection of ideas representing the peach as many distinct things. So the result would be another version of an idea of a medium betwixt unity and number. If the idea of identity through time were a way of addressing Hume's Difficulty, then this idea of simplicity amidst complexity would be as well.

\section{The fiction of pure substance}

When we first acquire the idea of identity, it is from the contemplation of a steadfast object. We have a habit of regarding everything to have duration and can't help but try to regard the steadfast object as having it even though it manifestly does not. The alternation of viewpoints is a way the mind tries to obscure the incompatibility of attributing being many to something manifestly one. That the object is manifestly one is lost, however, in the subsequent application of the idea of identity to successions of related objects. It is in such cases that we feign some cause of unitariness to compensate for the fact that the objects are manifestly many. For 
example, in the case of the fiction of personal identity we feign "a soul, and self, and substance" (THN 1.4.6.6).

The same thing happens in the case of taking a bundle of qualities to be a single individual. The qualities are manifestly many, but to justify the viewpoint of them as one and unitary, we feign a pure substance. What happens in the mind when we are feigning a pure substance? The mind represents the peach as many via the collection of ideas of its qualities. But how does the mind represent the peach as one simple thing? Hume doesn't say. My guess is that the mind uses the idea of simplicity in general, i.e. uses any simple idea regarded just insofar as it is simple. ${ }^{30}$

So the strong relation between the qualities leads the mind to attribute simplicity to them. This is "considering them as an unite" in the strongest sense. The manifest multiplicity of the qualities puts pressure on this attribution, which leads to the fiction of an unknown and unknowable pure substance to justify it. The pure substance is meant to provide the deep simplicity of a manifest multiplicity. The result is the fiction of a complex individual substance made a unity by a pure substance.

\section{Perceptions and Qualities as substances}

Since there are strictly speaking no complex things to count as individual substances, then if there are individual substances they have to be simple. The definition of individual substance that Hume relies on is again "something which may exist by itself." However, Hume says, "this definition agrees to every thing, that can possibly be conceiv'd; and never will serve to distinguish substance from accident,

${ }^{30}$ Likewise in feigning the fiction of a soul underlying identity through time, the mind would use the idea of steadfastness in general. 
or the soul from its perceptions" (THN 1.4.5.5). Among the things we can conceive are qualities and perceptions. So qualities and perceptions are individual substances, by that definition. ${ }^{31}$

Here Hume directly attacks Locke’s assumption about “those Qualities, we find existing, which we imagine cannot subsist, sine re substante, without something to support them" (ECHU 2.23.2). To the contrary, Hume argues that their independent existence is easily conceived.

Hume argues this to be the case with a compressed argument that glosses over a number of distinctions he ought to be making. The argument makes use of his Separability Principle, which is really a family of principles that should be teased apart. $^{32}$

Hume holds that all things numerically distinct are separable in reality, and conversely. Let me call this principle, the Real Separability Principle. Strictly speaking, it is not a principle for Hume, since he derives it from two others: what I will call the Mental Separability Principle and the Conceivability Principle.

Hume states the Mental Separability Principle early on:

First, We have observ'd, that whatever objects are different are distinguishable, and that whatever objects are distinguishable are separable by the thought and imagination. And we may here add, that these propositions are equally true in the inverse and that whatever

\footnotetext{
31 See THN 1.4.5.24 and the discussion of this passage in my section II.

32 Garrett speaks simply of the Separability Principle and says it and its converse are new with Hume (1997: 58). See also Bricke 1980: 68. However, see Descartes's discussion of distinctions in Principles, Part I, Principles LX-LXII, in CSM: 160-212, as well as medieval and ancient antecedents such as those cited in Bosley 2006. See Laird against the mental separability principle (1931: 82-83).
} 
objects are separable are also distinguishable, and that whatever objects are distinguishable are also different. (THN 1.1.7.3)

I assume from context that by "in the inverse" Hume means what we mean by 'conversely'.

When Hume says 'different' he means numerically distinct. For instance, in discussing time, he argues that the impression of time that one has in hearing five musical notes is not "different" from the impressions of the notes themselves, which is to say it is "not a sixth impression" (THN 1.2.3.10). Were it different, it would be a sixth impression, i.e., numerically distinct. Likewise at one point he explicitly uses the phrase 'numerically different'. ${ }^{33}$

When Hume says that things are "distinguishable," he means that we can think of them as numerically distinct. As he argues in his passage on distinctions of reason, where we cannot think of things as numerically distinct, they are "in effect the same and undistinguishable." Any apparent distinguishing of "them" is really a distinguishing of things related to "them." ${ }^{34}$

When Hume says objects are "separable by the thought and imagination" he means that it is possible to cease thinking of one while continuing to think of the other. Presumably we would do this by ceasing to have an idea of the one while continuing to have an idea of the other. When things are inseparable by the thought and imagination it is not possible to think of one while ceasing to think of the other. For instance, "A person, who desires us to consider the figure of a globe of white

33 THN 1.3.1.1.

34 THN 1.1.7.18. For additional discussion of less than numerical distinction see section VI. 
marble without thinking on its colour, desires an impossibility" (THN 1.1.7.18). ${ }^{35}$

So the Mental Separability Principle is that objects are numerically distinct only if we can think of them as distinct, and we can think of them as distinct only if we can continue to think of one while ceasing to think of the other.

Presumably we mentally separate the objects of thought by separating during the course of thinking the vehicles of thought--the ideas. For example we might mentally separate a cause and an effect by separating during the course of thinking the idea of the cause from the idea of the effect. Assuming that this is correct, Hume must be presupposing another proposition about separability: if ideas are distinct then they are separable in the course of thought. Call it the Idea Separability Principle. As a shortcut in reasoning, he will sometimes use the Idea Separability Principle interchangeably with the Mental Separability Principle, but strictly speaking they should be distinguished.

Note that to retain an idea of one thing while ceasing to have an idea of the other is to clearly think of the first thing as existing without the other.

The other main principle is the Conceivability Principle. Hume says that "nothing of which we can form a clear and distinct idea is absurd and impossible" (THN 1.1.7.6), and "'Tis an establish'd maxim in metaphysics, that whatever the mind clearly conceives includes the idea of possible existence, or in other words, that nothing we imagine is absolutely impossible" (THN 1.2.2.8), and "Whatever is clearly conceiv'd may exist; and whatever is clearly conceiv'd, after any manner, may exist

35 Cf. Descartes who uses the phrases "only distinct . . . by thought" and "differ only in thought." The Principles of Philosophy, Part I, Principle LXII 'Of the distinction created by thought' in CSM. 
after the same manner" (THN 1.4.5.5), and "whatever we conceive is possible" (THN 1.4.5.10). Here Hume uses a principle tracing back to Bishop Tempier's condemnations in 1277 , that the clearly conceivable is possible. ${ }^{36}$

Using the two main principles, Hume reasons as follows:

1. If things are distinct, then we can think of them as distinct, i.e. can clearly conceive of one continuing to exist without the other.

2. The clearly conceivable is possible.

3. So the one can continue to exist without the other.

In other words, he uses the Conceivability Principle to infer from the Mental Separability Principle a result about real separability—viz., that any numerically distinct things are really separable. Call this result the Real Separability Principle. ${ }^{37}$ There are three places in which Hume uses this reasoning about external objects. ${ }^{38}$

The use that concerns us here, the third, occurs in his discussion of substance. Unfortunately he adds a new level of complexity by appealing to the mental separability of ideas themselves as objects of thought. He is clear that he is adding this new level:

As we conclude from the distinction and separability of their ideas, that external objects have a separate existence from each other; so when we make these ideas themselves our objects, we must draw the

\footnotetext{
36 See Bosley and Tweedale 1997: editors' introductions, pp. xx-xxi, 440-441. See also Grant 1982.

${ }^{37}$ Note that the converse this principle follows easily, since nothing can exist without itself.

38 THN 1.2.5.3, 1.3.3.3, and 1.4.5.5.
} 
same conclusion concerning them, according to the precedent reasoning. (THN 1.4.5.27)

He here starts with the separability of ideas as vehicles of thought when thinking of external objects, and then moves via an implicit appeal to the mental separability of the external objects to the real separability of the external objects. Then he endorses the same reasoning from the separability of ideas as vehicles of thought when thinking of ideas to the real separability of those ideas being thought of. He is summarizing what he argued a little earlier: ${ }^{39}$

Whatever is clearly conceiv'd may exist; and whatever is clearly conceiv'd, after any manner, may exist after the same manner. This is one principle, which has been already acknowledg'd. Again, every thing, which is different, is distinguishable, and every thing which is distinguishable, is separable by the imagination. This is another principle. My conclusion from both is, that since all our perceptions are different from each other, and from every thing else in the universe, they are also distinct and separable, and may be consider'd as separately existent, and may exist separately... (THN 1.4.5.5)

The argument goes as follows:

1. A perception is numerically distinct from everything else in the universe.

\footnotetext{
${ }^{39}$ The same reasoning recurs in the Appendix to the Treatise: "Whatever is distinct, is distinguishable; and whatever is distinguishable, is separable by the thought or imagination. All perceptions are distinct. They are, therefore, distinguishable, and separable, and may be conceiv'd as separately existent, and may exist separately, without any contradiction or absurdity" (THN App.12).
} 
2. So, the perception is mentally separable from everything else (by separating the ideas of them in the course of thought).

3. So the perception is really separable from everything else. 1. is given. 2. follows by the Mental Separability Principle. 3. then follows by the Conceivability Principle.

It is important in understanding this argument to distinguish the real separability of perceptions from the idea separability of perceptions as vehicles of thought. In this argument, Hume is proving that perceptions are substances. They can exist independently of any of the other perceptions making up the mind that they are in (or any other perceptions for that matter), and so can exist independently of the mind--the bundle of perceptions--that they are in (and of any other bundle).

Now as every perception is distinguishable from another, and may be consider'd as separately existent; it evidently follows, that there is no absurdity in separating any particular perception from the mind; that is, in breaking off all its relations, with that connected mass of perceptions, which constitute a thinking being. (THN 1.4.2.39)

So a detailed understanding of Hume requires making these distinctions between the mental separability of objects, the real separability of objects, the idea separability in the course of thought of the ideas used in thinking, the mental separability of ideas, and the real separability of ideas. These are the five different ways in which Hume appeals to separability.

The argument that perceptions are substances continues as follows: 
4. So a perception can exist by itself.

5. So by definition a perception is a substance.

Hume has argued that perceptions are substances. He could argue in just the same way that qualities are substances. Any quality is really separable from anything that it is numerically distinct from. Therefore it can exist by itself. Therefore it is a substance, by definition. So Hume has shown that what Locke considers mere modifications of substances--perceptions and qualities--are substances themselves.

\section{No such thing as inhesion}

Hume continues the line of thought about perceptions and qualities to conclude that they do not inhere in anything. "Inhesion in something is suppos'd to be requisite to support the existence of our perceptions. Nothing appears requisite to support the existence of a perception. We have, therefore, no idea of inhesion" (THN 1.4.5.6). It follows as well that there is no such thing as inhesion.

One might think that Hume has gone too fast. He has argued that perceptions and qualities can exist independently of anything they are numerically distinct from. That, however, does not show that they don't inhere in anything. They may only be modally distinct from the substances they inhere in. The definition of substance as "something which may exist by itself" should be understood as something which may exist without anything it is numerically distinct from and without anything it is modally distinct from. 
Suarez takes the modal distinction to be a less than numerical distinction involving asymmetric inseparability. The mode is inseparable from the substance, but not vice-versa. ${ }^{40}$

Hume does seem to attribute to "theologians" some sort of less than numerical distinction between substance and modification. Their three criticisms of Spinoza that he presents depend on taking differences between modes to apply to the undifferentiated substance that they depend on. That is fair only if the modes are not numerically distinct from the substance. As Hume says, according to "the scholastic way of talking ... a mode, not being any distinct or separable existence, must be the very same with its substance ... " ${ }^{41}$ So the supposed distinction between mode and substance is not supposed to be numerical distinction.

However, Hume would take the notion of a less than numerical distinction as untenable. He would criticize it the way Ockham criticized Scotus's formal distinction. As Ockham puts it, "But among creatures the same thing cannot be truly affirmed and truly denied of the same thing." According to Ockham, if there is any difference between two (created) things then they are numerically distinct. ${ }^{42}$ Hume does not state this principle explicitly but appears to presuppose it when he says the following of a compound, altering body that we regard as a simple, identical thing: “The acknowledg'd composition is evidently contrary to this suppos'd simplicity, and the variation to the identity" (THN 1.4.3.2). Identical things cannot differ. As we would put it, he holds Leibniz's Law.

${ }^{40}$ Suarez 1947: sect. 2, no. 6, p. 44. See also Descartes, Principles I.LXI in CSM. 41 THN 1.4.5.22-25.

42 Ockham exempts things pertaining to God, such as the Persons of the Trinity. William of Ockham, Ordinatio I, distinction ii, qu. 6, in Spade 1994: 156. 
If a substance is independent of any other existent whatsoever, whereas a mode is not, then they differ. If they differ they are numerically distinct. So they are not merely modally distinct.

Confirmation that Hume considered and rejected any sort of modal distinction is given when he says, "Our perceptions are all really different, and separable, and distinguishable from each other, and from every thing else, which we can imagine; and therefore 'tis impossible to conceive, how they can be the action or abstract mode of any substance" (THN 1.4.5.27).

One might object that Hume himself gives an example of asymmetric inseparability. A whole cannot strictly speaking exist without having all its parts. "But supposing some very small or inconsiderable part to be added to the mass, or substracted from it; tho' this absolutely destroys the identity of the whole, strictly speaking; yet as we seldom think so accurately," etc. (THN 1.4.6.8). The parts, being distinct, are all separable from each other. So a part can exist without the whole. So here is an asymmetric inseparability. Hakkarainen argues that this asymmetric inseparability forces us to recognize a third type of distinction in Hume. In addition to real distinctions (i.e. numerical distinctions) and distinctions of reason (i.e. conceptual distinctions) we must see Hume as committed to what Hakkarainen, following David Lewis, calls a "partial distinction." This partial distinction is a special version of the modal distinction for wholes and their parts.

Hakkarainen is candid that Hume explicitly countenances no such third distinction. However, he contends, Hume needs it to resolve a glaring contradiction 
between Hume's Separability Principle and the fact that Hume explicitly says that wholes depend on their parts. ${ }^{43}$

I think there is a better way to go that is truer to the text. Hume has said that the definition of a substance--"something which may exist by itself"--applies to "every thing, that can possibly be conceiv'd" (THN 1.4.5.5). If a whole can be conceived, then it can't depend on its parts. It must be able to exist without them. So a whole is not a thing that can possibly be conceived. As Hume's Malezieu argument concluded, a whole of parts, strictly speaking, does not exist. "It" is nothing but the many parts, perhaps in some relation. Clearly they cannot exist collectively unless each of them exist. But each can exist without them all existing collectively. These facts give the appearance of asymmetric inseparability if wholes are said to exist. However, there is no asymmetric inseparability between things that strictly speaking exist.

Thus Hume has an answer to the charge that his rejection of inhesion overlooked the possibility of a modal distinction between mode and substance. So he can safely conclude that inhesion is impossible.

\section{No such thing as pure substance}

If there is such a thing as a pure substance, it is the principle of unity and identity for an individual in which accidents inhere. As Locke says, it is "the supposed, but unknown support of those Qualities, we find existing, which we imagine cannot subsist ... without something to support them," and which is the "Cause of their Union" in an individual substance (ECHU 2.23.2, 6). However, first, nothing can be a principle of unity and identity for a collection of distinct qualities,

${ }^{43}$ Hakkarainen 2012: 56-7. 
nor a succession of them, as argued in II and III. Adding an additional thing to several distinct things does not result in unitariness. ${ }^{44}$ Second, nothing can be something in which something that differs from it inheres, since there is no such thing as inherence, as argued in VI. There is no dependence between numerically distinct things and no modal distinction. For these two reasons individually and jointly, there is no such thing as pure substance.

Appeal to a principle of unity and identity in which distinct accidents inhere is the way that substance/accident theorists like Locke try to have complex unities without them breaking up into numerically distinct independent existences. However for Hume, the breakup is unavoidable, given (i) the Convertibility of Unity and Being, (ii) the Real Separability principle, and (iii) Leibniz's Law. From there it is up to natural psychological principles to explain why we hold the fiction of complex unities--a fiction so firmly believed that philosophers dreamt up the theory of substance and accident to try to capture it. ${ }^{45,46}$

${ }^{44} \mathrm{Cf}$. Aristotle, "A substance cannot consist of substances present in it in complete reality (Aristotle 1941, Metaphysics VII.13, 1039a2-14). See also Leibniz's claim "that a substance is not divisible into two" (Discourse on Metaphysics, section 9, in AG).

45 See THN 1.4.3.1.

46 I'm grateful to Toby Napoletano for research assistance. 